\title{
Proposta de Jogo Digital para Dispositivos Móveis: Desenvolvendo Habilidades do Pensamento Computacional*
}

\author{
Gustavo Pinho $^{1}$, Yuri Weisshahn ${ }^{1}$, Simone Cavalheiro $^{1}$ \\ Gerson Cavalheiro $^{1}$, Clause Fátima de Brum Piana ${ }^{1}$ \\ ${ }^{1}$ Centro de Desenvolvimento Tecnológico - Universidade Federal de Pelotas (UFPel) \\ Caixa Postal 354 - 96.010-610 - Pelotas - RS - Brazil \\ \{gcdpinho, simone.costa, gerson.cavalheiro\}@inf.ufpel.edu.br
}

\begin{abstract}
This paper describes the results of application of activity Caça ao Tesouro, approaching concepts of data search, developed in the ambit of Computational Thinking. The differential is the development of a digital game as instrument to execution of their tasks. It's presented the conception of this application and realized a comparison of the results of its application with the goals by the method classic using manufactured materials. The article documents the application results of the new conception of activity in terms of appropriation of the content and usability of the instrument.
\end{abstract}

Resumo. Este artigo descreve os resultados da aplicação da atividade Caça ao Tesouro, abordando conceitos de busca de dados, desenvolvida no âmbito do Pensamento Computacional. O diferencial é o desenvolvimento de um jogo digital como ferramenta para execução de suas tarefas. É apresentada a concepção deste aplicativo e realizada uma comparação dos resultados de sua aplicação com os obtidos pelo método clássico empregando materiais manufaturados. $O$ artigo documenta os resultados da aplicação da nova concepção da atividade em termos de apropriação do conteúdo e da usabilidade da ferramenta.

\section{Introdução}

Jeannete Wing descreveu o conceito de Pensamento Computacional (Computational Thinking) [Wing 2006], como uma metodologia para resolução de problemas, desenvolvimento de sistemas e entendimento do comportamento humano pela combinação do pensamento crítico e fundamentos da Computação. Neste contexto, habilidades aplicadas na criação de programas computacionais para resolução de problemas específicos são utilizadas como metodologia para solucionar problemas gerais, das mais diversas áreas do conhecimento [Bundy 2007, Denning 2009].

As escolas de Ensino Fundamental podem ser consideradas veículos para implantação do uso do Pensamento Computacional (PC), no intuito de desenvolver o raciocínio lógico-dedutível dos alunos, principalmente nos primeiros anos escolares. Diversos projetos e iniciativas sobre PC, neste contexto, comprovam esta afirmação. Algumas frentes de trabalho em diferentes níveis de ensino são promovidas por empresas multinacionais, como a Google que propôs um conjunto de atividades do PC para auxiliar

${ }^{*}$ Projeto realizado com o apoio do PROEXT - MEC/SESu. 
V Congresso Brasileiro de Informática na Educação (CBIE 2016)

Anais do XXVII Simpósio Brasileiro de Informática na Educação (SBIE 2016)

alunos do ensino primário e secundário dos EUA ${ }^{1}$. A Microsoft, em conjunto com a Universidade de Carnegie e Mellon, criou o Centro de Pensamento Computacional, em 2007 [Carnegie Mellon 2013]. [Lee et al. 2011] consiste em um artigo que analisa o PC, e recomenda sua disseminação, propondo um framework, use-modify-create, que representa três fases de atividades cognitivas e práticas dos alunos no PC.

No Brasil, também surgiram iniciativas nessa direção encabeçadas pela academia, registradas em diferentes trabalhos, como [França et al. 2015, Falcão and Barbosa 2015, Hinterholz and da Cruz 2015, Bombasar et al. 2015, Campos et al. 2014]. Em nível nacional, existe um esforço da comunidade para que o PC também passe a compor parte das diretrizes curriculares da educação básica brasileira. Em geral, grande parte dos projetos ativos utilizam recursos lúdicos construídos com materiais comuns (papelão, caixas e garrafas) para aplicação de atividades que desenvolvam habilidades do PC. Esta opção de materiais permite reduzir tanto as restrições para sua aplicação como seu orçamento. No entanto, recursos para interatividade providos por dispositivos móveis também podem permitir a realização de atividades do PC, com teores lúdicos similares, na forma de jogos. Considerando ainda a popularização e cobertura de dispositivos móveis, que registrou, em março de 2016, uma densidade de 125,42 celulares com acesso à Internet a cada 100 habitantes $^{2}$, pode-se inferir que as restrições ao uso deste recurso tendem a diminuir.

Os jogos digitais são uma forma de entretenimento muito popular entre públicos de todas as idades. Nos Estados Unidos, grande parte das residências possuem pelo menos um dispositivo com capacidade de executar jogos comerciais (computador, console, smartphone) [ESA 2012]. No Brasil, cerca de 23\% da população são jogadores casuais ou assíduos, o que corresponde a cerca de 45 milhões de jogadores ${ }^{3}$. Segundo [Azevedo 2012, Pescador 2010], jogos podem ser utilizados para potencializar a aprendizagem em diversas áreas do conhecimento. Existe, também, uma área dedicada à aplicação de jogos na aprendizagem, denominada de Digital Game-Based Learning [Van Eck 2006] que tem, dentre seus objetivos, a utilização de games comerciais para a aprendizagem de determinados conteúdos escolares [Azevedo 2012].

Inserido nesse meio, surge o conceito de gamificação. A gamificação consiste na utilização de princípios associados aos jogos, como mecânicas, estratégias e pensamentos, fora do contexto de games [Werbach 2012]. Diversos trabalhos exploram prós e contras do uso de gamificação na educação como, por exemplo, [Becker and Nicholson 2016]. Neste trabalho, o objetivo passa a ser motivar os indivíduos à ação, auxiliar na solução de problemas e promover aprendizagem, conforme destacado em [Kapp 2012].

O presente artigo tem como objetivo relatar o projeto, implementação e aplicação de um jogo educativo, voltado ao nível fundamental, para desenvolvimento da habilidade de busca de dados. Este jogo foi criado a partir de uma atividade previamente concebida denominada de Caça ao Tesouro. A metodologia empregada visa desenvolver habilidades

\footnotetext{
${ }^{1}$ Fonte Google: http://www.google.com/edu/computational-thinking/, acesso em maio/2016

${ }^{2}$ Fonte Anatel: http: //www. anatel.gov.br/dados/index.php/destaque-1/283movel-acessos-maio, acessado em maio/2016.

${ }^{3}$ Fonte UOL: http: / / www1. folha . uol.com.br/tec/1165034-mercado-brasileirode-games-ja-e-o-quarto-maior-do-mundo-e-deve-continuar-a-crescer. shtml, acessado em maio/2016.
} 
V Congresso Brasileiro de Informática na Educação (CBIE 2016)

Anais do XXVII Simpósio Brasileiro de Informática na Educação (SBIE 2016)

específicas do PC, utilizando conceitos de gamificação e de aparatos tecnológicos (tablets, smartphones, etc.) para despertar o interesse do aluno, materializando, neste jogo, a realização de uma atividade desenvolvida no contexto do PC.

O restante deste artigo está organizado como segue. A Seção 2 apresenta a metodologia de concepção da atividade Caça ao Tesouro, seguido da Seção 3, que expõe o significado de atividade no meio do PC. A Seção 4 descreve a metodologia de aplicação da atividade, tais como materiais e planos de aula. A Seção 5 apresenta o projeto e desenvolvimento da ferramenta de auxílio da atividade, seguido da Seção 6, que contém a avaliação da ferramenta e dos resultados obtidos. Por fim, a Seção 7 compreende as considerações finais acerca do trabalho.

\section{Metodologia}

Este trabalho teve seu início com a adaptação da atividade Batalha Naval, proposta no livro Computer Science Unplugged [Bell et al. 2010], visando o desenvolvimento da habilidade de busca de dados. Esta atividade foi adaptada para aplicação na forma clássica, utilizando materiais de baixo custo (papéis, caixas e garrafas), sem o uso do computador. Foram concebidas cinco tarefas, conduzidas e aplicadas em três turmas diferentes, uma destas em uma escola no centro de Pelotas, e as demais em uma escola de periferia deste mesmo município. A experiência da aplicação desta atividade permitiu conceber um jogo educativo digital implementando-a nesta nova plataforma.

O game design foi elaborado a partir de um jogo já existente. O processo de criação de sua versão digital iniciou-se, portanto, da especificação da narrativa e seus personagens. Isto é, da estória do jogo e de seus atores no universo digital. Foi utilizado o modelo de desenvolvimento de jogos denominado "Documento de Game Design" fornecido pelo ministrante da disciplina de Jogos, do curso Bacharelado em Design Digital da UFPel. A implementação propriamente dita do software foi, a exemplo do que ocorre na metodologia clássica de aplicação de atividades do PC, caracterizada por não limitar a aplicação das atividades pelo custo ou acessibilidade dos recursos materiais necessários. Desta forma, foram selecionadas ferramentas multiplataforma gratuitas para implementação do jogo.

Uma primeira versão do jogo foi concebida e aplicada em uma turma de estudantes de uma escola de periferia. A análise do uso deste protótipo indicou que a aplicação do jogo poderia ser bem sucedida em substituição ao método clássico, conforme registrado na Subseção 6.1. No entanto, durante a aplicação, foi possível observar que os princípios de gamificação não foram suficientes para atrair os jovens estudantes. Uma outra versão do jogo foi então elaborada, com uma nova interface. A arte e projeto desta nova interface foi concebida, por estudantes de Design, após estes receberem uma imersão sobre os conceitos de PC e da atividade em questão.

\section{Atividade no Pensamento Computacional}

Uma atividade, no âmbito do Pensamento Computacional, pode ser concebida como um conjunto de tarefas visando a elaboração de um fundamento da Ciência da Computação. As tarefas são concebidas para desenvolver o fundamento em questão, incentivando o raciocínio lógico-dedutível. É importante que as atividades sejam projetadas com base na realidade do público-alvo. No caso do projeto em que o presente trabalho se insere, 
V Congresso Brasileiro de Informática na Educação (CBIE 2016)

Anais do XXVII Simpósio Brasileiro de Informática na Educação (SBIE 2016)

o público-alvo encontra-se em escolas públicas, o que frequentemente significa dispensar o uso de aparatos tecnológicos. Dessa forma, a solução exequível é produzir uma atividade lúdica empregando como ferramental de apoio materiais manufaturados e/ou confeccionados com material reciclado, utilizando de conceitos de gamificação, sem uso do computador/smartphone.

O número de tarefas depende da concepção da atividade e, normalmente, cada tarefa introduz parte dos conceitos associados à habilidade em desenvolvimento. Elaborada em caráter lúdico, espera-se, ao final da aplicação da atividade, que a habilidade desejada tenha sido desenvolvida pela turma. A promoção da habilidade envolvida é usualmente mensurada pela aplicação de uma tarefa final, na qual é realizada uma avaliação sobre os conteúdo abordado.

Existem diversos programas e projetos com foco na elaboração de atividades para o desenvolvimento do PC nos diversos níveis de ensino, como: [Bell et al. 2010, Carnegie Mellon 2013, Rodriguez et al. 2015, UFPel 2016]. O livro Computer Science Unplugged [Bell et al. 2010], elaborado pelas universidades de Carnegie Mellon e de Canterbury, com o apoio da Google, descreve vinte propostas de atividades visando o ensino de fundamentos da Ciência da Computação sem o uso do computador.

Integrando as premissas anteriores, embora o uso de aparatos tecnológicos não seja essencial para a execução de uma atividade do PC, acredita-se que seu uso pode trazer vantagens relacionadas ao interesse do aluno. Agregando dispositivos com o conceito de gamificação, torna-se possível a criação de um jogo que transcreve a atividade lúdica, com um perfil atrativo e diferenciado. Para aplicação da atividade, é necessário um número considerável de dispositivos computacionais (computadores, tablets e smartphones) com o software que implementa suas tarefas para uso dos alunos; e uma máquina acompanhada de um projetor de imagem para exibir o jogo em um tamanho visível a todos. É importante a caracterização dos materiais da atividade para que as suas futuras aplicações sejam delimitadas pela condição de disponibilidade de tais equipamentos.

\section{Concepção da Atividade}

O conceito de estrutura de dados, na Ciência da Computação, é uma forma de armazenamento e organização de um dado, permitindo sua utilização de forma eficiente. A habilidade do PC busca de dados é a forma de obter uma informação em alguma estrutura de dados.O escopo da atividade se limita a três tipos de busca: linear, binária e hashing.

Essa habilidade pode ser exemplificada em atividades usuais de crianças em idade escolar, como a identificação do local onde uma figura deva ser adesivada em um álbum de coleção ou de um determinado card em um baralho ordenado. Na escola, alunos também enfrentam esta questão quando buscam livros, usualmente ordenados pelo nome/sobrenome do autor, seguido do título da obra.

A atividade tema desse artigo foi elaborada, sem o uso de aparatos tecnológicos, para aplicação no quinto ano do Ensino Fundamental da rede pública municipal de Pelotas a partir da atividade original Batalha Naval [Bell et al. 2010]. É válido mencionar que outros conceitos, além da busca de dados, também são explorados, de forma indireta, como abstração de dados e decomposição de problemas. Nesta Seção é apresentada a metodologia de uma adaptação da Batalha Naval, denominada de Caça ao Tesouro (CT), 
mantendo o objetivo e os principais conceitos da atividade original, mas utilizando de um jogo para dispositivos eletrônicos em sua aplicação. Neste jogo, o aluno é representado por um pirata que esconde seu próprio tesouro em uma ilha e procura o tesouro de um pirata adversário, que também escondeu seu tesouro em outra ilha. $\mathrm{O}$ pirata adversário pode ser um colega ou a própria máquina por uma lógica de jogo automática. Cada jogador contempla a localização de todas as suas ilhas, mas somente o nome das ilhas adversárias (sem localização).

A nova aplicação da atividade foi concebida com 5 tarefas, aplicadas em 5 encontros de 1 hora e 30 minutos. Cada tarefa abordando conceitos e exercícios específicos de um dos aspectos associados à habilidade de busca de dados. A CT consiste em um jogo de turnos, que possui três diferentes modos que variam a sua jogabilidade. Cada jogador detém um tabuleiro, compreendido por um conjunto de ilhas, tendo que escolher em qual delas esconder seu tesouro. Cada ilha, por sua vez, possui duas informações: uma letra, que representa seu nome, e um número, que simboliza sua localização. A disputa ocorre pela busca do tesouro do oponente, ganhando aquele que encontrar primeiro. Na tela do dispositivo é apresentado o tabuleiro, e oferecidos recursos de interação para esconder e realizar a busca pelo tesouro. A descrição das tarefas é apresentada a seguir.

\subsection{Tarefa I: Busca Linear}

Motivação: O objetivo da tarefa é apresentar o jogo e suas principais funcionalidades e também o de introduzir o conceito de busca linear a partir das experiências dos alunos.

Metodologia: Inicialmente são apresentadas as principais funcionalidades dos componentes do jogo, tais como tabuleiro, ilhas e tesouro, e seu enredo. Então, o conceito de busca linear é demonstrado por meio de partidas realizadas com a turma. O objetivo do jogo é encontrar a localização da ilha em que se encontra o tesouro adversário, de modo que a localização das ilhas estão distribuídas aleatoriamente. No restante da aula, os estudantes são instruídos a jogar contra a máquina, enquanto são observados pelo professor.

\subsection{Tarefa II: Busca Binária}

Motivação: A tarefa tem como objetivo dar continuidade à atividade, introduzindo o conceito de busca binária em conjunto com o modo de jogo equivalente ao conceito, isto é, a localização das ilhas estão distribuídas de forma ordenada.

Metodologia: A sequência da aula corresponde ao mesmo padrão da tarefa anterior, em que é apresentado o novo modo de jogo (busca binária), demonstrado por meio de partidas contra os alunos que, em seguida, são instruídos a jogar contra a máquina.

\subsection{Tarefa III: Busca Hashing}

Motivação: Nessa tarefa, o último conceito (hashing) é ensinado.

Metodologia: Seguindo o mesmo padrão das tarefas anteriores, o novo conceito é introduzido em partidas contra o professor. As ilhas são organizadas em dez colunas (0 a 9). É possível encontrar em qual coluna está o tesouro, aplicando módulo 10 à localização do tesouro adversário. Após, os alunos são instruídos a jogar contra a máquina, com a observação do professor.

\subsection{Tarefa IV: Revisão dos Conceitos Abordados}

Motivação: O objetivo dessa tarefa é acoplar os conceitos abordados em uma aula de revisão, praticando com os alunos todos os modos de jogo e sanando suas dúvidas. 
V Congresso Brasileiro de Informática na Educação (CBIE 2016)

Anais do XXVII Simpósio Brasileiro de Informática na Educação (SBIE 2016)

Metodologia: Propõe-se uma revisão dos conceitos abordados por meio de partidas contra a turma, em todos os modos. Também é nesta tarefa que são destacadas as diferenças, relacionadas em número de operações necessárias, dos distintos métodos de busca. Em seguida, os alunos são liberados para jogar em qualquer modo, sanando suas dúvidas à medida que surgem. Se os dispositivos utilizados na aplicação da atividade permitirem conexão bluetooth, não havendo dúvidas pendentes, são permitidos jogos de disputa entre dois alunos.

\subsection{Tarefa V: Avaliação}

A última tarefa consiste na avaliação da atividade, com o objetivo de medir o aprendizado dos alunos. O exame é realizado em papel (exatamente como feito na aplicação sem recursos tecnológicos, com o intuito de comparar os resultados), contendo exercícios condizentes com os conceitos abordados em aula, podendo haver questões teóricas e similares à execução do jogo. Na aplicação desta tarefa a avaliação consistiu em dois questionários. Um destes questionários é o tradicional de avaliação de conhecimento, sendo composto por 5 questões, algumas com mais de uma pergunta, totalizando 17 subquestões. O segundo questionário teve por objetivo exclusivo avaliar a ferramenta em si, composto por 14 questões, permitindo avaliar a aceitação da nova forma de aplicação do atividade.

\section{Projeto e Desenvolvimento}

Desenvolveu-se uma estória para o jogo com o objetivo de apresentar, aos usuários, os personagens e um contexto que permeia o Caça ao Tesouro. O enredo do aplicativo é descrito como segue. "Em um época distante, piratas habitavam os oceanos, navegando com seus enormes e perigosos navios. Dois grandes grupos de marujos dominavam o meio e, por isso, possuíam as mais diversas riquezas. Mas, como todo bom pirata, eram dominados por maus hábitos, como trapacear, disputando entre si para obter cada vez mais riquezas. Eventualmente, ao sair em busca de outros tesouros, os piratas escondiam sua fortuna em ilhas espalhadas pelo mundo."

O Caça ao Tesouro é um jogo de tabuleiro e estratégia, no qual cada um dos jogadores assume o papel de líder de um grupo pirata que, em turnos, enfrenta outro com o objetivo de encontrar o seu tesouro. Para que isso aconteça, primeiro cada pirata necessita escolher, no tabuleiro, uma ilha para esconder seu próprio tesouro. Para encontrar o tesouro do pirata oponente, cada jogador precisa fazer um palpite, procurando descobrir a localização do tesouro do adversário. Ganha aquele que encontrar o tesouro de seu oponente primeiro.

Para tornar o jogo atrativo foram introduzidas mecânicas de recompensas baseadas em princípios de gamificação e ilustrações que despertassem o interesse do públicoalvo. Dentre as mecânicas de jogo, busca-se cativar o usuário implantando um sistema de pontuação inversamente proporcional ao número de palpites necessários para encontrar o tesouro adversário, e o sistema de ranking que busca premiar o jogador, apresenta em destaque sua pontuação mais alta e incentiva-o à suplantá-la. O grafismo do jogo foi construído após uma interpretação de vários materiais de literatura infantis na temática proposta. A Figura 1 ilustra a proposta adotada com a imagem dos dois principais personagens do jogo: os piratas representando o jogador e seu adversário.

$\mathrm{O}$ aplicativo possui versões para desktop e para o universo mobile (tablets e smartphones). Entretanto, seu principal foco de implementação é para dispositivos 


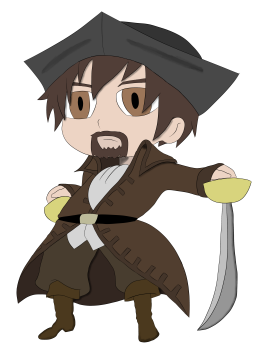

a) Personagem do usuário.

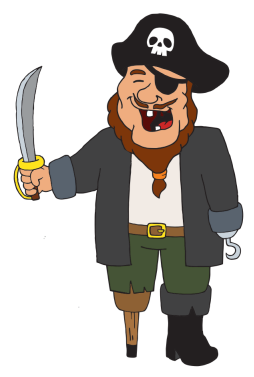

b) Personagem adversário.

Figura 1. llustrações dos Personagens do Jogo.

móveis, preocupando-se em desenvolvê-lo para as principais plataformas do mercado (Windows Phone, Android e iOS) ${ }^{4}$, tornando-o multiplataforma. Caça ao Tesouro é desenvolvido em linguagem web (Javascript, HTML e CSS), no framework Cordova, que realiza a compilação do programa em linguagem nativa da plataforma estipulada, executando o aplicativo no webview do dispositivo.

Como mencionado na Seção 2, a interface do jogo foi aperfeiçoada por designers e ilustradores, com o objetivo de tornar a experiência do usuário mais agradável e despertar seu interesse. Na Figura 2, é possível observar os materiais utilizados para a aplicação da atividade na forma clássica e a evolução da interface do jogo.

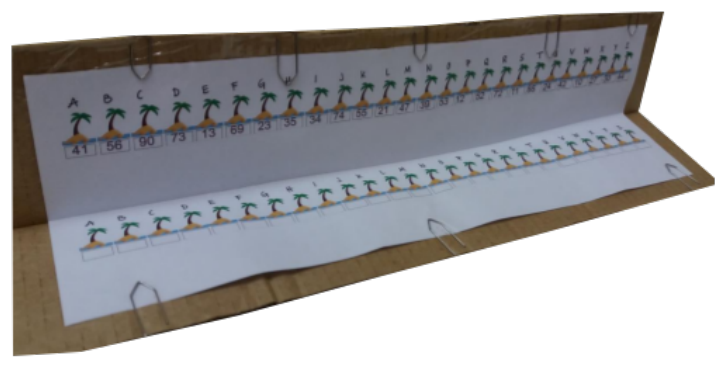

a) Tabuleiro da atividade CT (clássica).

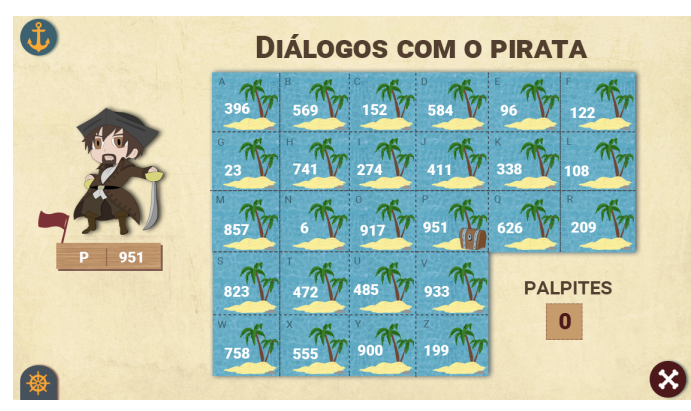

b) Tela do jogo (nova interface).

Figura 2. Materiais Utilizados na Aplicação da Atividade na Forma Clássica e com o Uso do Jogo.

\section{Avaliação da Ferramenta}

Houve a preocupação em testar o jogo em diversas plataformas para comprovar a aplicação do conceito de multiplataforma, embora grande parte do desenvolvimento tenha sido realizado sob a plataforma Android. O jogo foi testado e operou corretamento sobre as seguintes plataformas: Windows 7, Windows 8, Windows 10; Ubuntu 14.04 LTS, Ubuntu 15.10, Ubuntu 16.04 LTS (desktop); Android 4.8, Android 5.2, Android 5.8, Android 6.1 e iOS 8.4 (mobile).

Para avaliação da ferramenta, realizou-se a aplicação da atividade CT, com o uso do software produzido, para 27 alunos do $5^{\underline{0}}$ ano do Ensino Fundamental, com faixa etária

\footnotetext{
${ }^{4}$ Fonte IDC: http://www.idc.com/prodserv/smartphone-os-market-share.jsp, acessado em maio/2016.
} 
V Congresso Brasileiro de Informática na Educação (CBIE 2016)

Anais do XXVII Simpósio Brasileiro de Informática na Educação (SBIE 2016)

entre 9 e 14 anos, sendo $48 \%$ do sexo masculino e $52 \%$ do sexo feminino. Para viabilizar a avaliação do uso do software, uma equipe de 6 colaboradores monitorou a aplicação das atividades. Durante a execução da segunda tarefa, um teste de usabilidade, exemplificado na Figura 3a, foi realizado com vistas a avaliar a dificuldade e a jogabilidade do aplicativo. Ao final, em conjunto com a avaliação da atividade, foi aplicado um outro questionário, ilustrado na Figura 3b, com o objetivo de avaliar o jogo em geral, junto com a metodologia utilizada para aplicação da atividade. A Tabela 1 apresenta o resultado médio da avaliação da aplicação de CT clássico, nas três turmas, e da aplicação com o uso do aplicativo.

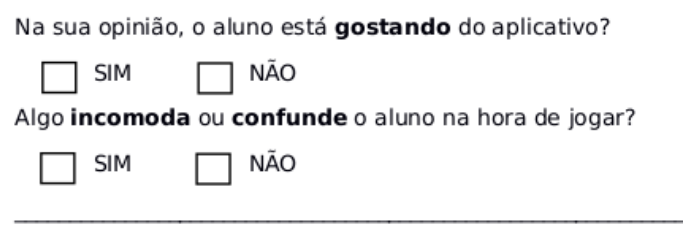

a) Questões do teste de usabilidade.

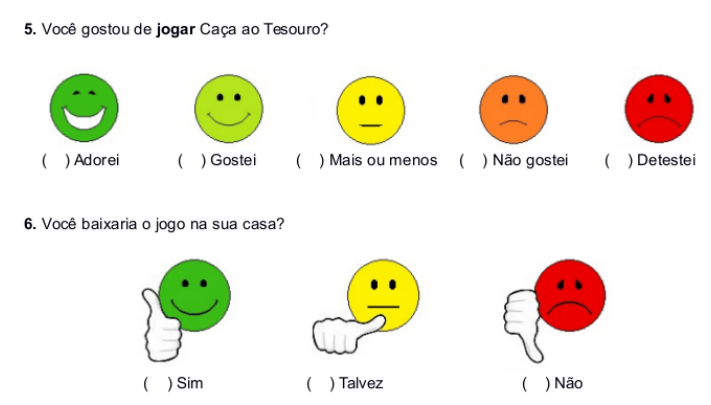

b) Questões do teste de avaliação do jogo.

Figura 3. Questões dos Testes Aplicados aos Alunos.

Tabela 1. Descrição do desempenho dos alunos na avaliação, segundo a forma de aplicação da atividade Caça ao Tesouro.

\begin{tabular}{c|ccc|ccccc}
\hline Forma de Aplicação & $\mathrm{n}$ & Média & $\mathrm{DP}$ & Mínimo & $Q_{1}$ & $\mathrm{Md}$ & $Q_{3}$ & Máximo \\
\hline Clássica & 66 & $6,2 \mathrm{a}$ & 1,90 & 2,2 & 4,9 & 6,21 & 7,5 & 10 \\
Aplicativo & 24 & $6,8 \mathrm{a}$ & 1,53 & 4,7 & 5,3 & 7,3 & 7,9 & 9,5 \\
\hline
\end{tabular}

Nota: $\mathrm{n}$ = número de alunos; $\mathrm{DP}=$ desvio padrão; $Q_{1}=$ primeiro quartil;

$\mathrm{Md}=$ mediana; $Q_{3}=$ terceiro quartil. Médias seguidas de mesma letra não

diferem entre si pelo teste $\mathrm{t}(\alpha=0,05)$

Tabela 2. Descrição das respostas dos alunos nos testes de usabilidade e de
avaliação do jogo.
\begin{tabular}{c|ccccc} 
Teste & nQ & nA & R. Positivas & R. Negativas & R. Intermediárias \\
\hline Usabilidade & 11 & 24 & $83 \%$ & $13 \%$ & $4 \%$ \\
Avaliação & 14 & 24 & $87 \%$ & $3 \%$ & $10 \%$ \\
\hline
\end{tabular}
Nota: nQ = número de questões; nA = números de alunos; R. = respostas.

\subsection{Análise dos Resultados}

O desempenho médio das três turmas submetidas à metodologia clássica não diferiu significativamente do desempenho médio da turma submetida ao método com o uso do aplicativo, segundo o teste $t$, com $\alpha=0,05$. Embora seja possível observar na Tabela 1 uma média superior na forma de aplicação com o uso do software $(6,8)$, não é possível concluir sua superioridade.

Por outro lado, colaboradores do projeto e o próprio professor da escola, que acompanharam ambas as aplicações, observaram que os alunos se mostraram bem mais 
V Congresso Brasileiro de Informática na Educação (CBIE 2016)

Anais do XXVII Simpósio Brasileiro de Informática na Educação (SBIE 2016)

motivados na execução da atividade com o uso do computador. Ademais, a portabilidade dos dispositivos móveis facilita a disponibilização do jogo, permitindo que os estudantes fixem os conceitos abordados fora do contexto escolar.

Existem diversos fatores que precisam ser considerados para afirmar que determinada forma de aplicação obtém melhores resultados. Desse modo, embora seja evidente a eficiência do jogo para aplicação da atividade CT, é necessário realizar um estudo mais aprofundado e levar em consideração outros fatores como perfil da turma, dinamicidade do professor, período de aplicação da atividade, não abordados nesse artigo, para de fato concluir qual a melhor forma de aplicação.

Espera-se que os resultados obtidos pela aplicação da atividade com o uso de tecnologia estimulem o emprego de outras formas de interação no ensino-aprendizagem. Dada a crescente evolução e popularização da tecnologia, grande parte da população possui pelo menos um dispositivo móvel e faz parte de alguma rede social, o que pode ser observado entre os alunos. Entende-se que a sua familiarização com esses aparatos tornase um instrumento motivacional para aprendizagem em sala de aula.

\section{Considerações Finais}

Este artigo contribui com uma proposta metodológica da atividade Caça ao Tesouro, objetivando o incentivo ao desenvolvimento de habilidades do Pensamento Computacional, como busca e abstração de dados. Além disso, contribui com avaliação do uso de aparatos tecnológicos como ferramentas para aplicação de tarefas de uma atividade, como alternativa aos métodos clássicos que utilizam materiais manufaturados e/ou reciclados.

A aplicação da atividade na forma de um jogo obteve o resultado desejado, com grande parte dos alunos obtendo uma avaliação de apropriação das habilidades acima da média registrada pela aplicação da mesma atividade na forma clássica. Os estudantes foram muito bem receptivos à atividade apoiada em recursos computacionais e, a maioria, como observado na Tabela 2, aprovou a atividade e o uso do aplicativo desenvolvido. A atividade Caça ao Tesouro também foi importante para aproximação da comunidade com a Universidade, uma vez que a aplicação das tarefas, em função da necessidade de recursos computacionais, deu-se nos laboratórios do curso de Ciência da Computação. Este fato, por si só, permitiu uma experiência nova aos alunos, embora reflita a falta de oportunidades oferecidas pelo ensino público. Espera-se que a experiência sirva para promover o desenvolvimento de futuras atividades com o uso de recursos tecnológicos.

Para conclusão da concepção da ferramenta, espera-se reaplicá-la para teste e aceitação da nova interface, visando, em trabalhos futuros, que sejam desenvolvidos novos jogos a partir de atividades já concebidas no projeto em que este trabalho se insere. Outro experimento a ser realizado consiste na apresentação dos conceitos trabalhados a uma turma de mesma faixa etária, mas sem o uso de jogos, permitindo uma comparação com os resultados já obtidos.

\section{Referências}

Azevedo, V. (2012). Jogos eletrônicos e educação: construindo um roteiro para a sua análise pedagógica. RENOTE: Novas Tecnologias na Educação, 10(3).

Becker, K. and Nicholson, S. (2016). Gamifying the classroom: Pros and cons. 
V Congresso Brasileiro de Informática na Educação (CBIE 2016)

Anais do XXVII Simpósio Brasileiro de Informática na Educação (SBIE 2016)

Bell, T., Witten, I. H., and Fellows, M. F. (2010). Computer Science Unplugged.

Bombasar, J. R. et al. (2015). Ferramentas para o ensino-aprendizagem do pensamento computacional: onde está alan turing? In SBIE 2015, pages 81-90.

Bundy, A. (2007). Computational thinking is pervasive. Journal of Scientific and Practical Computing, 1:67-69.

Campos, G. et al. (2014). Organização de informações via pensamento computacional: Relato de atividade aplicada no ensino fundamental. In WIE 2014, pages 390-399.

Carnegie Mellon (2013). Center for Computational Thinking. http://www.cs.cmu.edu/ CompThink/. Acesso: maio/2016.

Denning, P. J. (2009). The profession of it: Beyond computational thinking. Commun. ACM, 52(6):28-30.

ESA (2012). Entertainment software association: 2012 essential facts about the computer and video game industry. http://www.theesa.com/facts/pdfs/ESA_EF_2012.pdf. Acesso: maio/2016.

Falcão, T. P. and Barbosa, R. S. (2015). "aperta o play!"análise da interação exploratória em um jogo baseado em pensamento computacional. In SBIE 2015, pages 419-428.

França, R. et al. (2015). Desafios e oportunidades ao ensino do pensamento computacional na educação básica no brasil. In CBIE 2015, pages 1464-1473.

Hinterholz, L. T. and da Cruz, M. E. K. (2015). Desenvolvimento do pensamento computacional: Um relato de atividade junto ao ensino médio, através do estágio supervisionado em computação iii. In WIE 2015, pages 137-146.

Kapp, K. (2012). The gamification of learning and instruction: Game-based methods and strategies for training and education.

Lee, I. et al. (2011). Computational thinking for youth in practice. ACM Inroads, 2(1):3237.

Pescador, M. C. (2010). Ações de aprendizagem empregadas pelo nativo digital para interagir em redes hipermidiáticas tendo o inglês como língua franca.

Rodriguez, C. L. et al. (2015). Pensamento computacional: transformando ideias em jogos digitais usando o scratch. In WIE 2015, pages 62-71.

UFPel (2016). EXP-PC - Explorando o Pensamento Computacional para a Qualificação do Ensino Fundamental. http://wp.ufpel.edu.br/pensamentocomputacional. Acesso: maio/2016.

Van Eck, R. (2006). Digital game based learning: It's not just the digital native who are restless. http://net.educause.edu/ir/library/pdf/ERM0620.pdf. Acesso: maio/2016.

Werbach, K.; Hunter, D. (2012). For the win: How game thinking can revolutionize your business. Wharton Digital Press.

Wing, J. M. (2006). Computational thinking. Communications of the ACM, 49(3):33-35. 